\title{
The attractiveness of conspecific and interspecific odor for bank voles Clethrionomys glareolus
}

\author{
Roman ANDRZEJEWSKI, Joanna BABIŃSKA-WERKA, Anna LIRO, \\ Edyta OWADOWSKA and Jakub SZACKI
}

\begin{abstract}
Andrzejewski R., Babińska-Werka J., Liro A., Owadowska E. and Szacki J. 1997. The attractiveness of conspecific and interspecific odor for bank voles Clethrionomys glareolus. Acta Theriologica 42: 231-234.

We investigated the reaction of bank voles Clethrionomys glareolus (Schreber, 1780) to odors of conspecific individuals and that of wood mice Apodemus sylvaticus (Linnaeus, 1758) in a mature forest in central Poland $\left(52^{\circ} 20^{\prime} \mathrm{N}, 27^{\circ} 25^{\prime} \mathrm{E}\right)$. Our results show no difference in catching bank voles in traps using conspecific or wood mouse odors as bait.

Catholic University of Lublin, Al. Racławickie 14, 20-950 Lublin, Poland (RA); Department of Game Management, Agricultural University of Warsaw, Rakowiecka 26/30, 02-528 Warsaw, Poland (JB-W); Kampinos National Park, Krasińskiego 9, 05-080 Izabelin, Poland (EO); National Foundation for Environment Protection, Krzywickiego 9, 02-078 Warsaw, Poland (AL, JS)
\end{abstract}

Key words: Clethrionomys glareolus, trappability, olfaction

\section{Introduction}

Most studies dedicated to the role of olfaction in small mammals were carried out either in laboratories (eg Hurst 1990) or in enclosures (eg Drickamer et al. 1992), and the role of olfactory cues for rodents living in the wild is still not sufficiently known. Many authors stressed the importance of olfaction in rodent social life (Rozenfeld et al. 1987, Tew et al. 1994, Drickamer 1995), but the role of odor seems to be even more important for orientation in a landscape. Some data show that small mammals may traverse much longer distances than it had been previously thought (Szacki et al. 1993) and olfaction may be the only source of navigational information. In fact, some data have suggested the significant role of olfactory trails for small mammal movements (Jamon 1994).

To date, studies of significance of odors for ecology of small mammals have shown that live-trapping of small mammals is often more efficient when conspecific individuals had earlier stayed in those traps (Montgomery 1979, Heske 1987, Tew 1987, Tew et al. 1994, Drickamer 1995). Other studies (Gurnell and Little 1992) have shown that trap attractivity is influenced by sex and age of individuals trapped previously. Most authors suggest that rodents tend to avoid odor of other 
species (eg Drickamer 1984, Merriam 1990), but it is apparently not always the case (Tew et al. 1994).

Studies of rodent reactions to odors of other individuals were carried out also in laboratories. Nyby et al. (1985) studied the influence of pheromones from individuals of different age and sex and compared them to the attractiveness of odors of different foods: sunflower seed, peanut butter, or standard food for laboratory mice. Andrzejewski and Owadowska (1994) developed an easy method for using rodent odors (not mixed with food odor) for bait and they successfully applied it when catching small mammals with snap-traps in a forest.

The aim of this study was to test the hypothesis that the effect of conspecific scent and that of other species are equally attractive when applied to traps.

\section{Study area and methods}

Differnces in atractiveness of different odors in a population of bank voles Clethrionomys glareolus (Schreber, 1780), were examined in an alder-wood [Carici elongate-Alnetum (Koch 1926) community] at an age of approximately 100 years. The forest was characterized by very dense undergrowth and it was located in Kampinos National Park, about $45 \mathrm{~km}$ west of Warsaw.

Six parallel lines of snap-traps were set in the forest. Each line was $850 \mathrm{~m}$ long and snap-traps were set at 10 meter intervals. The distance between lines was 150 meters. Two types of traps were used. In some traps release mechanisms consisted of wooden bases supporting polyurethane foam soaked with sunflower oil (common European bait). A trap of this kind is triggered by an animal pulling the foam. Traps supplied with odor baits were made of metal only. Their release mechanism reacted to an animal pressing the trap with its feet.

Odor bait was prepared in the laboratory. A few rodents of the same species were kept in each of several 2 liter glass jars. Two thirds of each jar was filled with sponge cubes (cube size was suitable for attaching to traps). While in a jar rodents were neither fed nor watered. Rodents spent 3 hours in a jar, 3 times daily. When not in jars, rodents were provided with food and water ad libitum (Andrzejewski and Owadowska 1994). Scent bait was obtained from bank voles (common in the field area) and wood mice Apodemus sylvaticus (Linnaeus, 1758) (rare in the area). At the time when the study was carried out, no individuals were sexually active. Therefore, we have assumed there was no difference in odors from different sexes, and so we randomly selected individuals (both sexes) for placement in the scent jars.

Different baits were placed along the trap lines in the following sequence: station 1: food bait; station 2: scent bait with bank vole odor; station 3: food bait; station 4: scent bait with wood mouse odor, etc., on all trap lines. Thus, the number of traps with food bait equaled the number of traps with two types of scent bait $(n=255+255)$. Half of the scent baits were supplied with bank vole odor and a half with wood mouse odor.

Traps were checked once a day. Species, sex and type of bait were recorded for every capture. Traplines were set for 6 days from 16 to 21 September 1993.

\section{Results}

A total of 240 bank voles, 5 yellow-necked mice Apodemus flavicollis, 5 wood mice, 2 field mice A. agrarius, 3 common shrews Sorex araneus, and 2 pygmy shrews $S$. minutus were captured. 
Ninety two individuals of 240 bank voles (or $38.3 \%$ ) were caught in traps with food bait, $76(31.7 \%)$ in traps with wood mouse odor and $72(30 \%)$ with bank vole odor. As the proportion of different types of traps was 2:1:1 (traps with food bait : traps with wood mouse odor : traps with bank vole odour), the expected distribution of catches is $120: 60: 60$. The difference between that distribution and the actual one was significant $\left(\chi^{2}=13.2, p<0.05\right)$. The number of individuals of other species was too small for statistical analysis. On average, $15.33 \pm 7.39$ bank voles were caught per day in traps with food bait, $12.67 \pm 5.13$ with wood mouse odor, and $12.00 \pm 5.76$ with bank vole odor. The statistical analysis (Student's $t$-test for paired dependent samples) shows that there is no difference between trappability of individuals caught in traps with wood mouse odor and those caught in traps with bank vole odor (for the whole interval $p>0.8$ ). The same statistical analysis indicates a significant difference in trappability in traps with odor bait and traps with food bait $(p<0.001)$.

\section{Discussion}

Most of field studies dedicated to olfaction in small mammals were conducted with the use of live-traps. Traps of this type change the spatial behavior of rodents (Sheppe 1967, Szacki et al. 1993). Besides, they have to contain some food to prevent animals from starving and this provides additional odor cues. If no food is supplied traps have to be checked very often and this is not always possible. For those reasons we decided to use snap-traps.

The results show that bank voles respond more strongly to odor of other rodents (of two species being studied) than to the smell of sun-flower oil. As the food-and odor-traps were of different type it is impossible to demonstrate that odor-bait is actually more attractive than the sunflower-oil. However, the results do show that odor-bait is at least as attractive as food bait.

The results presented suggest that both odor of conspecifics and odor of a species occurring sympatrically but at low densities are similarly attractive for bank voles. This suggests that bank voles are able to perceive olfactory cues left by conspecifics in a forest, and, to the same degree, odor originating from other species present in the area, in this case the wood mouse. Other studies have shown that the two sympatric species are competing under natural conditions (Andrzejewski and Olszewski 1963, Gurnell 1985, Kozakiewicz et al. 1987) and most other studies report that individuals tend to avoid heterospecific odors. However, Tew et al. (1994) have shown that bank voles do not avoid traps that had previously held wood mice. Our experiment does not show whether the similar reaction of bank voles to odors of both species is significant for competitive or cooperative reasons. It seems, however, that using other species scent to orient may increase individual fitness by improving foraging efficiency. Other studies involving more species would shed further light on the problem. 
Acknowledgments: We thank Prof W. Z. Lidicker, Jr for critical review of the paper and correcting our English. The project was financially supported by Kampinos National Park.

\section{References}

Andrzejewski R. and Olszewski J. 1963. Social behaviour and interspecific relations in Apodemus flavicollis (Melchior, 1834) and Clethrionomys glareolus (Schreber, 1780). Acta Theriologica 7: $155-168$.

Andrzejewski R. and Owadowska E. 1994. Use of odor bait to catch bank voles. Acta Theriologica 39: 221-225.

Drickamer L. C. 1984. Captures of two species of Peromyscus at live traps baited with male and female odors. Journal of Mammalogy 65: 699-702.

Drickamer L. C. 1995. Odors in traps: does most recent occupant influence capture rates for house mice? Journal of Chemical Ecology 21: 541-555.

Drickamer L. C., Mikesic D. G. and Shaffer K. S. 1992. Use of odor baits in traps to test reactions to intra- and interspecific chemical cues in house mice living in outdoor enclosures. Journal of Chemical Ecology 18: 2223-2250.

Gurnell J. 1985. Woodland rodent communities. Symposia of Zoological Society of London 55: $377-411$.

Gurnell J. and Little J. 1992. The influence of trap residual odor on catching woodland rodents. Animal Behaviour 43: 623-632.

Heske E. 1987. Responses of a population of California voles, Microtus californicus, to odor-baited traps. Journal of Mammalogy 68: 64-72.

Hurst J. L. 1990. Urine marking in populations of wild house mice Mus musculus Rutty. III. Communication between the sexes. Animal Behaviour 40: 233-243.

Jamon M. 1994. An analysis of trail-following behaviour in the wood mouse, Apodemus sylvaticus. Animal Behaviour 47: 1127-1134.

Kozakiewicz M., Kozakiewicz A. and Banach A. 1987. Effect of environmental conditions on the character of spatial interactions among three small rodent species. Bulletin of the Polish Academy of Sciences, Biological Sciences 35: 181-188.

Merriam G. 1990. Ecological processes in the time and space of farmland mosaics. [In: Changing landscapes: an ecological perspective. I. S. Zonneveld and R. T. T. Forman, eds]. Springer Verlag, New York: 121-133.

Montgomery W. I. 1979. An examination of interspecific, sexual and individual biases affecting rodent captures in Longworth traps. Acta Theriologica 24: 35-45.

Nyby J., Kay E., Bean N. J., Dahinden Z. and Kerchner M. 1985. Male mouse (Mus musculus) attraction to airborne urinary odors of conspecifics and to food odors: effects of food deprivation. Journal of Comparative Psychology 99: 479-490.

Rozenfeld F. M., Le Boulangé E. and Rasmont R. 1987. Urine marking by male bank voles Clethrionomys glareolus Schreber, 1780 (Microtidae, Rodentia) in relation to their social rank. Canadian Journal of Zoology 65: 2594-2601.

Sheppe W. 1967. The effect of live traping on the movements of Peromyscus. American Midland Naturalist 78: 471-481.

Szacki J., Babińska-Werka J. and Liro A. 1993. The influence of landscape spatial structure on small mammal movements. Acta Theriologica 38: 113-123.

Tew T. 1987. A comparison of small mammal responses to clean and dirty traps. Journal of Zoology, London 212: 361-364.

Tew T., Todd I. A. and Macdonald D. W. 1994. Temporal changes in olfactory preference in murid rodents revealed by live-trapping. Journal of Mammalogy 75: 750-756.

Received 5 July 1996, accepted 25 March 1997. 